\title{
To Review Postmodernism and its New Trends from the Oriental Perspective
}

\author{
Yue-ping WANG \\ Basic Dpt., Zhengzhou University of Science \& Technology, Zhengzhou 450000, \\ China
}

234571@qq.com

\begin{abstract}
Keywords: Postmodernism, Rewriting of history, Historiography, Postcolonial theorists.
\end{abstract}

\begin{abstract}
China skipped the transgressive, constestatory part of postmodernism and moved directly to the compromised, commercialized offspring. A question always haunts me: how can a common reader, with his mind being shaped by the conventional realistic thinking about history and without receiving enough teachings from postmodern historiography, be well conscious of the intention behind the apparent postmodern "falsifying" of history? Actually, I often observe two kinds of typical reactions to it: some would be very annoyed and think it as totally irresponsible lying, while some others would just enjoy it as light fantasies.
\end{abstract}

\section{Introduction}

I think Chinese postmodernism is and will be less( or more, in another sense) fortunate than its Western counterpart, since here is so big a commercial market, which, you know, has always proved to be an invincible power both for the cultural producers and consumers. Apparently, most postmodern tropes ( of quotations, allusion, irony, parody and so on) have been adopted in cultural productions, but the truly postmodern spirit, its overt or covert problem itemization of conventional thinking about truth, history, identity, gender and things like that is hard to observe. Hence we often hear from critics both at home and abroad expressing their disappointment about Chinese contemporary art. Probably, the commercial market in China has only fostered pop culture as its filial son, while infanticiding its unfilial children including postmodernism.

It is as if China skipped the transgressive, constestatory part of postmodernism and moved directly to the compromised, commercialized offspring. A question always haunts me: how can a common reader, with his mind being shaped by the conventional realistic thinking about history and without receiving enough teachings from postmodern historiography, be well conscious of the intention behind the apparent postmodern "falsifying" of history? Actually, I often observe two kinds of typical reactions to it: some would be very annoyed and think it as totally irresponsible lying, while some others would just enjoy it as light fantasies. It seems to me that most parodic rewriting of history, while questionizing the common reader's fixed knowledge about such-and-such historical facts indeed, may fail to induce acritical thinking about history as is expected. You are right that there is an audience problem here, and there always was (or is) with postmodernism. That's one of the reasons why the critical challenges to history through irony and parody were very blatant, very overt, in many cases: if they had been too subtle, people would have missed the critical point. Irony assumes a kind of "interpretive community" that can "get"/ understand the irony. After all, you are saying one thing and meaning another: 
that's the definition of irony.

\section{The Parodied History}

And if you don't have the right context or the right information, you will misunderstand the irony. If you don't know the "official" version of history that the historical novelist is parodying, then you won't "get" the parody, but will read it as either a light fantasy - to use your terms - or as irresponsible tampering with the fact. This is always a problem with irony and parody - and always has been. That what makes it subversive, perhaps: some people won't get it (and then the parodist is in a sense "safe" but misunderstood) but others will get it (and the parodist is transgressive, in that case, and much more threatening). How that parodist fares will depend on the social culture in which $\mathrm{s} / \mathrm{he}$ is living at the time. After surveying the problem, Wrangham offers two hypotheses to explain the evolution of self-delusion in combat. The "performance-enhancement hypothesis" suggests that "by suppressing conflicting thoughts or feelings, positive illusions enable individuals or groups to be more effective in achieving a goal." The "opponent-deception hypothesis" proposes that "humans tend to deceive themselves as a way to bluff successfully."The two hypotheses are mutually inclusive and suggest that, ultimately, "exaggerated assessment of the probability of winning increases the probability of winning." Overconfidence, delusion, unrealistic expectations, and overall self-deception can therefore be more adaptive - and therefore more useful - than the ability to assess a situation accurately and respond appropriately. Self-deception can be adaptive in non-combat situations as well. Over the past twenty years psychologist Shelly E. Taylor and her collaborators have produced more than two dozen articles examining the mental and physical benefits of "positive illusions," such as an inflated belief in one's own abilities, an exaggerated sense of control, or an unjustified optimism in the future. In the first of these articles, Taylor and Jonathon D. Brown take direct aim at the common belief among professionals that "the psychologically healthy person is one who maintains close contact with reality." They point to solid survey data showing that most people have an unrealistically positive perception of themselves, their abilities, and their ability to control events in their life.

If mental health is defined as having beliefs that align with reality, then most people would have to be considered mentally ill. However, they assert, evidence from converging sources suggests that positive illusions about the self, one's control, and the future may be especially apparent and adaptive under circumstances of adversity, that is, circumstances that might be expected to produce depression or lack of motivation. Under these circumstances, the belief in one's self as a competent, efficacious actor behaving in a world with a generally positive future may be especially helpful in overcoming setbacks, potential blows to self-esteem, and potential erosions inone's view of the future. In subsequent articles Taylor and others have presented evidence that positive illusions increase people's ability to recover from life-threatening diseases, combat aids, manage stress, and cope with extreme adversity. The effect of a positive illusion need not even be dramatic to be adaptive. Let's say that a seriously ill person who had only a 1 percent chance of recovery could increase this to a 2 percent chance through unrestrained, completely unjustifiable optimism. Over thousands of generations, this slight survival advantage would cause selection to favor the unrealistic optimists over the somber realists.

Clinical studies have repeatedly demonstrated that optimism and positive thinking in the seriously ill can increase chances of survival by far more than a single 
percentage point. Sexual selection, too, benefits from increased self-confidence even when such confidence is entirely unjustified. Confident people, especially confident men, are often seen as more attractive than unconfident people - even if their confidence is unfounded. Confidence accompanies material success or physical prowess often enough for potential mates to equate one with the other. In a long-term committed relationship, a woman can see through the bluster of an overconfident male. Yet, according to evolutionary psychologist David M. Buss this is not true in casual encounters, where confidence itself often proves inherently valuable. To illustrate how this works, Buss relates the following narrative from an interview with a single woman: I was sitting at a corner table talking to my girlfriend and sipping on a gin and tonic. Then Bob walked in. He walked into the bar like he owned the place, smiling broadly and very confident. He caught my eye, and I smiled. He sat down and started talking about how horses were his hobby. He casually mentioned that he owned a horse farm. When the last call for alcohol came, he was still talking about how expensive his horses were, and said that we should go riding together. He said, "In fact, we could go riding right now." It was 2:00 a.m., and I left the bar and had sex with him. I never did find out whether he owned horses.10The evolutionary value of these horses does not depend on their factual existence.

\section{The Important Traits of Political Potential}

It seems to me that political potential was one of the most important traits for what you thought could be counted as really postmodern. Was that true? What do you think now? And what is your opinion about the so-called "return to aesthetics." Have we had enough of politics in our literary studies? I think it is inevitable that there will be a reaction against whatever comes before. I also think that even moving to aesthetics is a political statement-it is a rejection of politics. We can't really escape politics entirely, at least in the sense of ideology. In the West, the rise of "identity politics" (feminism, queer theory, race studies, etc.) meant that politics has been very much in the foreground. Postmodernism rather sits on the fence: it contests but also exploits systems of power. Certainly, back in the 1980s and 1990s, the political counter discourses of the time were extremely nervous about the postmodern: feminists and postcolonial theorists knew that they shared with the postmodern a focus on the marginalized and the eccentric, on the local (rather than the universal) and the hybrid (rather than the pure).They too sought to deconstruct and dismantle cultural assumptions that had become dominant. But the counter-discourses we associate with identity politics, in particular, feared the absorption of their own specific interventionary and op-positional agenda - social and political agendas - into those of this generic category called post-modernism. They were deeply suspicious as well of the postmodern's apparent lack of a theory of political agency, its tendency to sit on the fence politically, thanks precisely to its inclusive both /and kind of thinking. Feminists were among the first to attack postmodernism's complicitous form of critique - that is, its tendency to deconstruct cultural monoliths, but never to offer suggestions for reconstructions. As Seyla Benhabib put it, postmodernism "in its infinitely skeptical and subversive attitude toward normative claims, institutional justice and political struggles", is certainly refreshing.

\section{The Comparisons between Hutcheon and the Leftists}

Yet it is also debilitating. Others took up this critique to argue once again that, for oppositional counter-discourses, the value of postmodern theory's suspicion of 
truth-claims and its denaturalizing and demystifying impulses had been compromised by its very success, its very institutionalization. Postmodernism's deliberate open-endedness, its "both-and" thinking, and its resolute lack of resolution risked immobilizing oppressed people. As postcolonial theorists insisted in the1990s, echoing feminists in the 1980s, it can be hard to achieve activist ends (with firm moral and ideological values) in a postmodern world where such values are not permitted to be grounded, where no utopian possibility is left unironized. Where does this leave the postmodern today? In the West in the $21^{\text {st }}$ century, all evidence is pointing to a realization that it is no longer enough to focus attention on the marginal and on the different as part of a demystifying process - though that focus may be considered a crucial first step to action. Other theories - ranging from the post-racial, post-national focus of cosmopolitanism to the exigencies of environmentalism-challenge the postmodern from different directions. Nevertheless, there are still some theorists-Elizabeth Deeds Ermarth among them-who keep reminding us of the positive political potential that still lies in what she calls the more "generous impulses of postmodernity": "the postmodern condition re-opens political options that the culture of modernity has increasingly suppressed by its search for unity, rationality, and non-contradiction. Postmodernity acknowledges and even features precisely the inescapability of contradiction, of unmediatable difference".

Many excellent comparisons have been made between your theory and that of the Leftists. In your advocacy for political literary studies, I think you are not far apart from the Left critics such as Terry Eagleton and Frederic Jameson, both famous for their political reading of literature. Some critics have argued that the postmodern critique against the liberal humanism had already been anticipated by Marxism, and even by Marx himself. And it is not difficult to observe the apparent Marxist impact upon postmodernists, although many of the latter eagerly declared their disregard of the former's legacy. So can you explain some essential difference (while I am aware of the anti-essentialist feature of postmodernism) between postmodernism and Marxism?

\section{Conclusion}

Marxism was certainly a major force in initiating the kind of rethinking of capitalist hegemony in Western politics, philosophy and the arts, and you are correct to say that the links with the postmodern critique of liberal humanism are strong. But it is also important to note that rather than making "class" the central issue, as does Marxism, postmodernism widened the political spectrum to include gender, race, sexuality, and so on. But the focus on the "ex-eccentric" or the non-central is decidedly a shared one. It was the French philosopher Jean-Francois Lyotard who defined the postmodern as a suspicion of meta-narratives, a distrust of "grand re-cites"-like the Marxist "emancipatory" narrative - and that's where the anti-universalizing end.

\section{References}

[1] Anderson, Benedict. Imagined Communities: Reflections on the Origins and Spread of Nationalism. London: New Left, 1983.

[2] Appiah, Kwame Anthony. Cosmopolitanism: Ethics of a World of Strangers. New York and London: W. W. Norton \& Company, 2006.

[3] Barthes, Roland. "The Death of the Author.” Image/Music/Text. Trans. Stephen 
Heath. New York: Farrar, Straus, and Giroux, 1977. 142-48.

[4] Clifford, James. Routes: Travel and Translation in the Late Twentieth Century. Cambridge: Harvard UP, 1997. 